\title{
Multi-Organ Involvement
}

National Cancer Institute

\section{Source}

National Cancer Institute. Multi-Organ Involvement. NCI Thesaurus. Code C123405.

A finding indicating the spread of a neoplastic process to multiple organs. 